\title{
Aplicação de silício aumenta a produtividade de grãos de amendoim
}

Stefania Fernandes (D)

Graduanda em Engenharia Agronômica pela Faculdade de Ciências Agrárias e Veterinárias - Fcav/ UNESP. Departamento de Ciências da Produção Agrícola; Universidade Estadual Paulista Júlio de Mesquita Filho.

Gilmara Pereira da Silva (DD Professora colaboradora da Universidade do Estado do Mato Grosso -UNEMAT. Universidade do Estado de Mato Grosso - UNEMAT, Campus Universitário de Alta Floresta, e-mail: gilmaraagronoma@gmail.com.

Renato de Mello Prado iD Professor do Departamento de Solos e Adubos; Universidade Estadual Paulista Júlio de Mesquita Filho. de Mesquita Filho.

\section{RESUMO}

O fornecimento de Si dependendo do modo de aplicação que pode ser aplicado via radicular (solo ou cultivo hidropônico) e via foliar e pode beneficiar a produtividade de plantas de amendoim. Portanto, objetivou-se avaliar o efeito da aplicação de Si nas formas radicular, pulverização foliar e Si via radicular somado a pulverização foliar no número de vagens por planta, peso de vagens e produtividade de plantas de amendoim. $O$ experimento foi realizado em casa de vegetação da UNESP, Jaboticabal, SP, em plantas de amendoim (Arachis hypogaea L.) cultivar granoleico. Para realização dos estudos, foram considerados os seguintes tratamentos: sem aplicação de Si (-Si); Si via radicular (Si R) $\left(2,0 \mathrm{mmol}^{-1}\right.$ ) Si via foliar (Si F) $\left(4,0 \mathrm{mmol}^{-1}\right)$ e Si via radicular com uso de solução nutritiva associado ao foliar (Si $\left.R+F\right)$, dispostos em blocos casualizado com cinco repetições. As plantas receberam solução nutritiva de Hoagland e Arnon com $25 \%$ da força iônica durante todo o desenvolvimento. A fonte de Si utilizada foi o silicato de sódio e potássio $\left(113,4 \mathrm{~g} \mathrm{~L}^{-1}\right.$ de Si e $18,9 \mathrm{~g} \mathrm{~L}^{-1}$ de $\mathrm{K}_{2} \mathrm{O}$ ), 0 potássio foi equilibrado em todos os tratamentos, utilizando cloreto de potássio. $A$ pulverização foliar foi realizada no início da manhã com a umidade do igual ou superior a $70 \%$ e temperatura baixo de $25^{\circ} \mathrm{C}$. Foram avaliados o número de vagens por planta, peso de vagens e produtividade de plantas de amendoim. 0 suprimento de Si, independente da forma de aplicação do elemento, incrementou o número e peso de vagens e aumentou a produtividade de grãos de amendoim.

Palavras-chave: Arachis hypogaea L.; Elemento benéfico; Formas de utilização.

\section{Application of silicon increases the productivity of peanut grain}

\section{ABSTRACT}

The Si supply depending on the application mode that can be applied via root (soil or hydroponic cultivation) and via leaf and can benefit the productivity of peanut plants. Therefore, the objective was to evaluate the effect of the application of Si in the root, leaf spraying and Si via root forms plus leaf spraying in the number of pods per plant, weight of pods and productivity of peanut plants. The experiment was carried out in a greenhouse at UNESP, 
Jaboticabal, SP, on peanut plants (Arachis hypogaea L.) cultivar granoleico. To carry out the studies, the following treatments were considered: without Si application (-Si); Si via root (Si R) $\left(2.0 \mathrm{mmol} \mathrm{L}^{-1}\right)$ Si via leaf (Si F) $\left(4.0 \mathrm{mmol} \mathrm{L}^{-1}\right)$ and Si via root using nutrient solution associated with the leaf $(S i R+F)$, arranged in randomized blocks with five repetitions. The plants received a nutrient solution from Hoagland and Arnon with $25 \%$ of ionic strength throughout the development. The source of Si used was sodium and potassium silicate $\left(113.4 \mathrm{~g} \mathrm{~L}^{-1}\right.$ of Si and $18.9 \mathrm{~g} \mathrm{~L}^{-1}$ of $\mathrm{K}_{2} \mathrm{O}$ ), potassium was balanced in all treatments, using potassium chloride. Leaf spraying was carried out in the early morning with a humidity of $70 \%$ or more and a low temperature of $25^{\circ} \mathrm{C}$. The number of pods per plant, weight of pods and productivity of peanut plants were evaluated. The supply of Si, regardless of the form of application of the element, increased the number and weight of pods and increased the productivity of peanut grains.

Keywords: Arachis hypogaea L.; Beneficial elemento; Ways of use.

\section{La aplicación de silicio aumenta la productividad del grano de maní}

\section{RESUMEN}

El Si aporta en función del modo de aplicación que se puede aplicar vía raíz (suelo o cultivo hidropónico) y vía foliar y puede beneficiar la productividad de las plantas de maní. Por tanto, el objetivo fue evaluar el efecto de la aplicación de Si en la raíz, la aspersión foliar y el Si vía formas radiculares más la aspersión foliar en el número de vainas por planta, peso de las vainas y productividad de las plantas de maní. El experimento se realizó en invernadero de la UNESP, Jaboticabal, SP, sobre plantas de maní (Arachis hypogaea L.) cultivar granoleico. Para la realización de los estudios se consideraron los siguientes tratamientos: sin aplicación de Si (-Si); Si vía raíz (Si R) $\left(2.0 \mathrm{mmol} L^{-1}\right)$ Si vía hoja (Si F) $\left(4.0 \mathrm{mmol} \mathrm{L}^{-1}\right)$ y Si vía raíz usando solución nutritiva asociada a la hoja (Si $R+F)$, dispuestos en bloques al azar con cinco repeticiones. Las plantas recibieron una solución nutritiva de Hoagland y Arnon con un $25 \%$ de fuerza iónica durante todo el desarrollo. La fuente de Si utilizada fue silicato de sodio y potasio $\left(113,4 \mathrm{~g} \mathrm{~L}^{-1}\right.$ de Si y 18,9 $\mathrm{g} \mathrm{L}^{-1}$ de $\mathrm{K}_{2} \mathrm{O}$ ), el potasio se equilibró en todos los tratamientos, utilizando cloruro de potasio. La aspersión foliar se realizó a primera hora de la mañana con una humedad igual o superior al $70 \%$ y una temperatura baja de 25oC. Se evaluó el número de vainas por planta, el peso de las vainas y la productividad de las plantas de maní. El aporte de Si, independientemente de la forma de aplicación del elemento, aumentó el número y peso de las vainas y aumentó la productividad de los granos de maní.

Palabras clave: Arachis hypogaea L.; Elemento beneficioso; Formas de uso.

\section{Introdução}

A aplicação de silício ( $\mathrm{Si}$ ) tem sido benéfica a diversas culturas, principalmente as consideradas acumuladoras de Si. Entretanto, estudos tem apontado que plantas dicotiledôneas, consideradas não acumuladoras de Si (<5 g kg-1 de Si) como o amendoim (Arachis hypogaea L.) (SHEN et al., 2014) também tem respondido à aplicação de Si.

Trabalhos tem mostrado que a aplicação de $\mathrm{Si}$ em plantas de amendoim tem promovido aumento no crescimento (SHEN et al., 2014), incremento nos teores de $\mathrm{Si}$, que levou a um aumento na produção de vagens e na produtividade de grãos de amendoim (CRUSCIOL et al., 2013). 
Contudo, para diagnosticar os efeitos benéficos do Si em plantas de amendoim é preciso conhecer a melhor forma de aplicação do elemento. Para o fornecimento do $\mathrm{Si}$ às plantas, que é absorvido na forma de ácido monossilícico (Souza Junior et al., 2020), tem-se a opção da aplicação via radicular (solo ou cultivo hidropônico) e via foliar.

Assim, tem-se a hipótese que o suprimento de Si em diferentes formas de aplicação tem efeito positivo no número de vagens por planta, peso de vagem e produtividade de plantas de amendoim.

Portanto, objetivou-se avaliar o efeito da aplicação de Si nas formas radicular, pulverização foliar e Si via radicular somado a pulverização foliar no número de vagens por planta, peso de vagem e produtividade de grãos de amendoim.

\section{Material e métodos}

O experimento foi realizado em casa de vegetação da UNESP, campus de Jaboticabal, SP, Brasil, no período de dezembro 2017 a abril 2018, em plantas de amendoim cultivar granoleico. Durante o período de estudo foram registrados os dados meteorológicos com 0 uso de termohigrômetro, referentes a temperatura máxima, mínima e umidade relativa média do ar, os quais estão demonstrados na Figura 1.

Para realização dos estudos, foram considerados os seguintes tratamentos: controle, sem aplicação de Si (-Si); aplicação de Si via radicular (Si R); aplicação de Si via foliar (Si F) e aplicação de $\mathrm{Si}$ via radicular associado a aplicação foliar $(\mathrm{Si} R+\mathrm{F})$. O delineamento amostral foi de blocos ao acaso com cinco repetições para cada tratamento.

As plantas foram cultivadas em vasos com capacidade de $7 \mathrm{dm}^{3}$ preenchidos com 6,5 $\mathrm{dm}^{3}$ de areia que recebeu solução nutritiva de Hoagland e Arnon (1950) com $25 \%$ da força iônica. O valor de $\mathrm{pH}$ da solução nutritiva foi mantida a $5,5 \pm 0,5$, a partir do uso da solução com $\mathrm{HCl}$ ou $\mathrm{NaOH}$ a 0,1 M. A fonte de Si utilizada foi o silicato de sódio e potássio 
(113,4 $\mathrm{g} \mathrm{L}^{-1}$ de Si e 18,9 $\mathrm{g} \mathrm{L}^{-1}$ de $\left.\mathrm{K}_{2} \mathrm{O}\right)$, o potássio foi equilibrado em todos os tratamentos, utilizando cloreto de potássio.

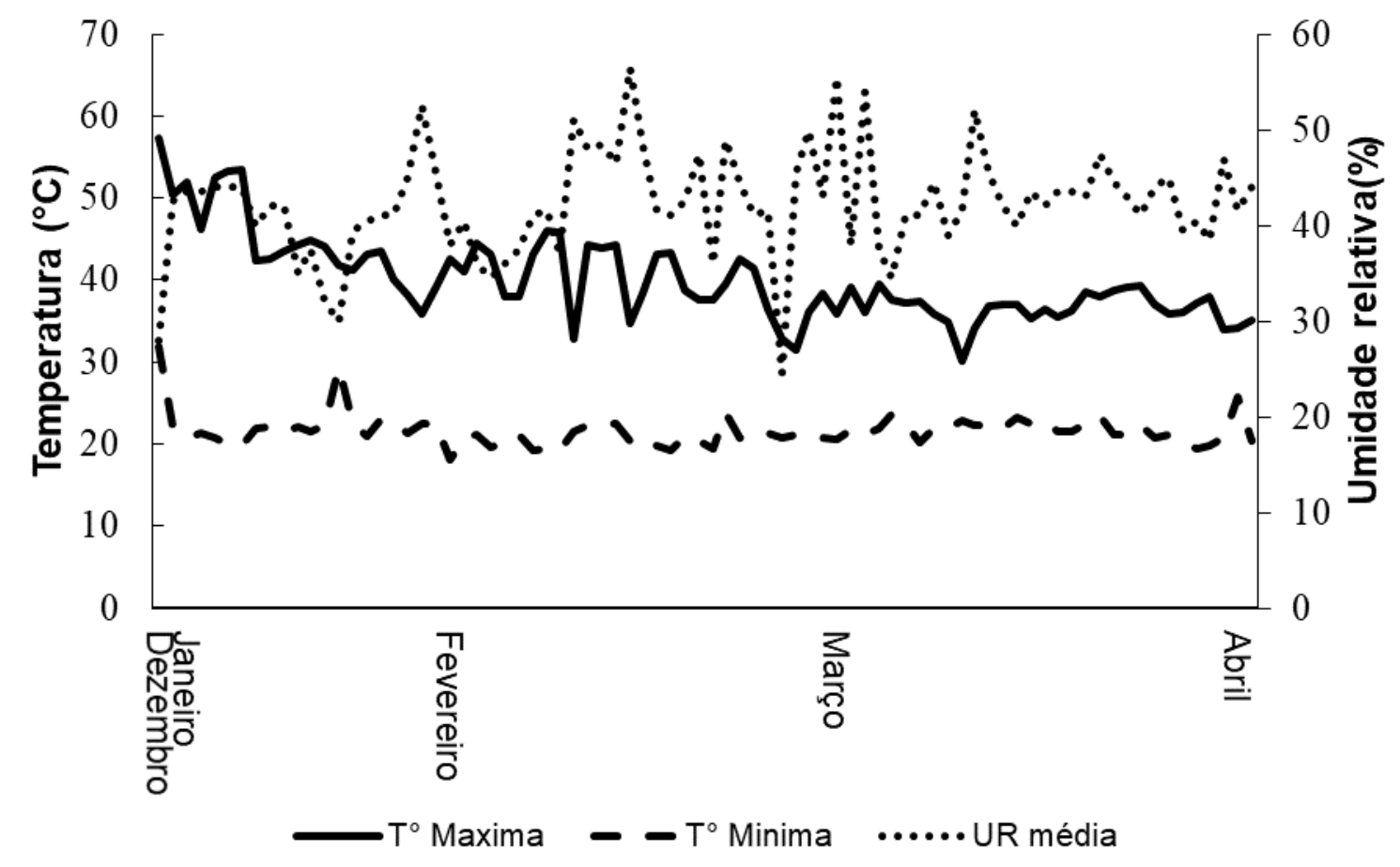

Figura 1. Temperatura máxima, mínima e umidade relativa média no interior da casa de vegetação no período de dezembro de 2017 a fevereiro de 2018.

O tratamento com zero concentração de Si (controle) foi mantido com solução nutritiva completa e sem uso de Si. Para obtenção do tratamento com Si via radicular foi utilizada solução nutritiva completa acrescida de Si na concentração de $2 \mathrm{mmol} \mathrm{L}^{-1}$. O tratamento com aplicação de Si via foliar foi realizado através da pulverização manuais com uso de borrifador na concentração de $4 \mathrm{mmol} \mathrm{L}^{-1}$ dissolvido em água deionizada, com pulverizações feitas cinco vezes na parte área da planta a cada sete dias iniciando aos quinze dias após a germinação das plântulas. Para o tratamento com aplicação de Si via radicular + Si via foliar foi utilizada solução nutritiva completa acrescida de Si da mesma forma que indicadas anteriormente. A pulverização foliar foi realizada no início da manhã com a umidade do igual ou superior a $70 \%$ e temperatura baixo de $250 C$. Neste momento a superfície dos vasos foram cobertos para evitar contaminação do substrato com $\mathrm{Si}$. 
Realizou-se a semeadura do amendoim em vasos, e após oito dias da emergência realizou-se desbaste deixando duas plantas por vaso e teve início a aplicação de solução nutritiva. A solução nutritiva foi aplicada todos os dias até atingir a saturação do substrato do vaso. Realizou-se indução da lixiviação nos vasos a cada sete dias com água deionizada a fim de evitar a salinidade do substrato, sendo que após duas horas da drenagem, retornava-se a solução nutritiva.

Na segunda planta, retirada noventa e dois dias após a germinação, em fase final do ciclo com a presença de vagens, foi realizada a contagem do número de vagens, determinação do peso das vagens e da produtividade de grãos.

Os resultados obtidos foram submetidos a análise de variância pelo teste $F(p<0,05)$ e as médias comparadas pelo teste de Tukey a $5 \%$ de probabilidade. $O$ estudo das relações entre as variáveis foi realizado por meio da correlação de Pearson usando o software Agroestat ${ }^{\circledR}$ (BARBOSA; MALDONADO JÚNIOR, 2016).

\section{Resultados e discussão}

$\mathrm{O}$ uso de $\mathrm{Si}$ independente da forma de aplicação incrementou o número de vagens por planta, peso de vagem e produtividade de grãos de amendoim (Figura 2). Contudo, para o número de vagens por planta a aplicação de Si Foliar de destacou em relação ao tratamento com ausência de Si (Figura 2a).

Além disso, o uso de Si via radicular foi importante para o aumento do peso de vagem e produtividade de plantas de amendoim em relação ao tratamento com ausência de Si (Figura 2b, c).

A aplicação de $\mathrm{Si}$, incrementou o número de vagens por planta, $\left(r=0,84^{*}\right)$, e o peso de vagem $\left(r=0,94^{* *}\right)$, levando a um aumento na produtividade de vagens do amendoim independente da forma de aplicação do elemento (Figura 2c), observado pela análise de correlação entre as variáveis. 
Crusciol et al. (2013) também relatam os efeitos benéficos do Si nas culturas da soja, feijão e amendoim, no qual foi verificado um incremento nos teores de $\mathrm{Si}$, que levou a um aumento na produção de vagens e na produtividade de grãos das culturas estudadas, provando a viabilidade agronômica dessa forma de fornecimento do elemento benéfico.

a)

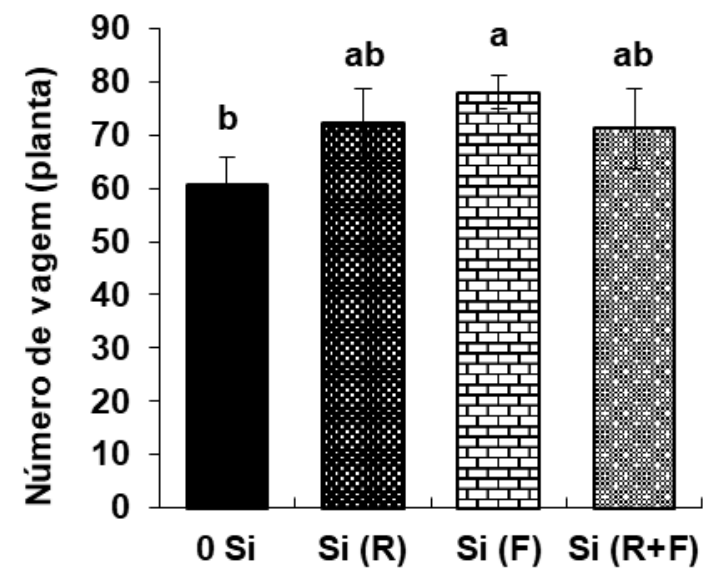

b)

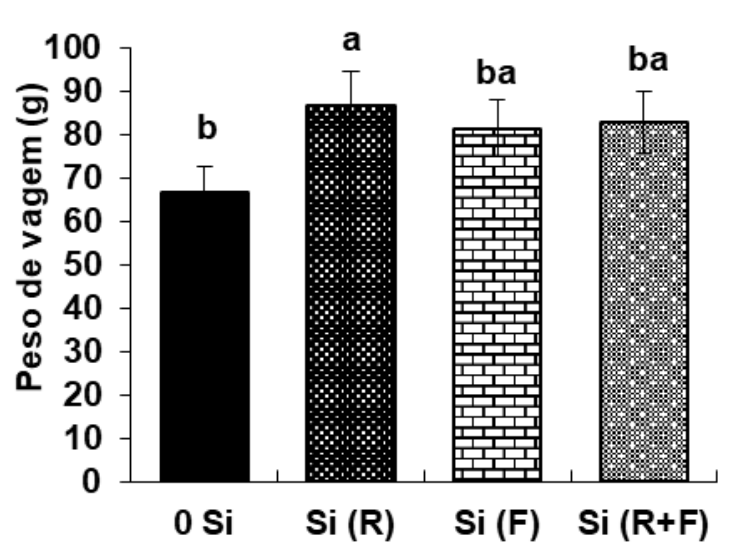

c)

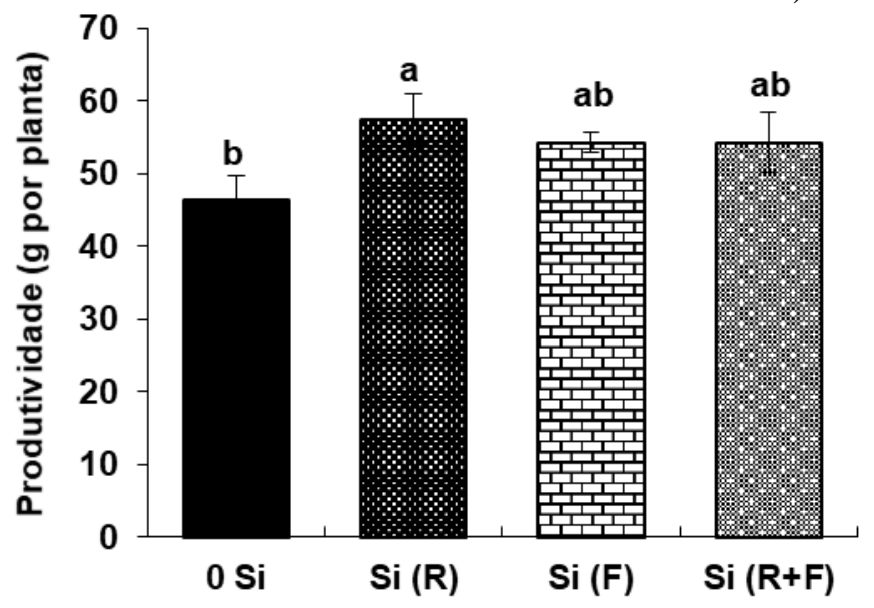

Figura 2. Número de vagens por planta (a), peso de vagens (b) e produtividade de grãos (c) de plantas de amendoim em função da aplicação de Si via radicular $\mathrm{Si}(\mathrm{R})$, pulverização foliar $\mathrm{Si}(\mathrm{F})$ e associação destas duas formas de aplicação $\mathrm{Si}(\mathrm{R}+\mathrm{F})$. Os valores representam a média \pm erro padrão.

\section{Conclusões}

O suprimento de $\mathrm{Si}$, independente da forma de aplicação do elemento, incrementou o número e peso de vagens e aumentou a produtividade de grãos de amendoim. 


\section{Agradecimentos}

Os autores prestam seus agradecimentos à Faculdade de Ciências Agrárias e Veterinário-UNESP - Campus de Jaboticabal, por propiciar o desenvolvimento do trabalho. 


\section{Referências}

BARBOSA, José Carlos; MALDONADO JÚNIOR, Walter. 2016. Experimentação agronômica \& Agroestat: sistema para análises estatísticas de ensaios agronômicos. Jaboticabal: Multipress, 2016. 396p.

CRUSCIOL, Carlos Alexandre Costa; SORATTO, Rogério Peres; CASTRO, Gustavo Spadotti Amaral; COSTA, Claudio Hideo Martins; FERRARI NETO, Jayme. Aplicação foliar de ácido silícico estabilizado na soja, feijão e amendoim. Revista Ciência Agronômica, v. 44, p. 404-410, 2013. Revista Ciência Agronômica. http://dx.doi.org/10.1590/S1806-66902013000200025

HOAGLAND, Dennis Robert; ARNON, Daniel Israel. The water culture methods for growing plants without soil. Calif Agric Exp Stn Circ, p.347:1-32, 1950. Calif Agric Exp Stn Circ.

SHEN, Xuefeng; XIAO, Xueming; DONG, Zhaoxia; CHEN, Yong. Silicon effects on antioxidative enzymes and lipid peroxidation in leaves and roots of peanut under aluminum stress. Acta Physiologiae Plantarum, v. 36, p.3063-3069, 2014. Acta Physiologiae Plantarum. http://dx.doi/10.1007/s11738-014-1676-8

SOUZA JUNIOR, Jonas Pereira; FRAZÃO, Joaquim José; MORAIS, Thais Barros Chagas, ESPOTI, Clara Degli; SANTOS, Macilene Machados dos Santos; PRADO, Renato de Mello. Foliar Spraying of Silicon Associated with Salicylic Acid Increases Silicon Absorption and Peanut Growth. Silicon, p.1-7, 2020. 